\title{
報
}

(Received February 6, 1984)

\section{DEFORMATION MECHANISM OF DRY GEL POLYETHYLENE UP TO A DRAW RATIO OF 300}

\author{
By Masaru Matsuo*, Kaori Inoue, and Noriko Abumiya \\ (Department of Clothing Science, Faculty of Home Economics, \\ Nara Women's University, Nara 630)
}

\begin{abstract}
Deformation mechanism of dry gel polyethylene film which can be elongated to a draw ratio of $\lambda=300$, was investigated in terms of morphological aspect by scanning electron microscopy, polarized microscopy, small angle X-ray scattering, wide angle X-ray diffraction, and small angle light scattering. Through a series of experimental results, the morphology of the dry gel films is found to be similar to that of single crystal mats and then the facile drawability is thought to be due to the transformation from a folded to a fibrous crystals. In this process, a suitable level of entanglements between crystal lamellae plays an important role to transmit the drawing force as intermolecular crosslinks.
\end{abstract}

\section{INTRODUCTION}

It is well-known that the theoretically attainable Young's modulus and tensile strength of polymeric materials can only be realized if the extended chains are fully aligned and if the specimen is almost completely crystalline. In attempts to produce such ideal samples, molecular alignment induced by deformation or flow has been extensively investigated. The spinning of liquid crystals, the surface growth method, the super-high speed melt spinning, and the gel deformation method can be enumerated as the representative examples.

The spinning of liquid crystals has been developed to produce strong fibers of synthetic polypeptide and aramide. These polymers have a low viscosity drag in spite of high concentrated solution, since the assembly of rigid chains behaves as a unit of flow on the spinning. The morphology of such assembly, as a model system of the spinning of liquid crystals, has been investigated for poly $(r$ -

* To whom all correspondence should be addressed.
benzyl-L-glutamate) (PBLG) liquid crystals under violent flow which is caused by applying an electric field to the liquid crystals. ${ }^{1-5)}$ The internal structure as a unit of flow was certainly confirmed to be an oriented rodlike texture in the direction of an electric field by $\mathrm{H}_{\mathrm{v}}$ light scattering technique and polarized microscopy. ${ }^{1-7)}$ However, it should be noted that the existence of such textures becomes a serious limit naturally to produce extremely aligned and extended chains. Actually, as pointed by Matsuo et al. ${ }^{1-5)}$ the $\mathrm{H}_{\mathrm{v}}$ scattering experiments indicated that the molecular chain axes within the rod have the orientational fluctuation with respect to the rod axis and consequently the molecular axes are not so highly aligned in the flow direction.

The surface growth method has been developed by Pennings et al. ${ }^{8)}$ and Keller et al.9) to produce strong polyethylene fibers. According to their reports, the best values of the Young's modulus and the tensile strength were $142^{8)}$ and $4.7 \mathrm{GPa}^{9}$, respectively. Unfortunately, this method has disadvantage that the production rate of the longi- 
tudinal crystal is far below commercially interesting speed.

By contrast, the super-high speed melt spinning has played an important part to produce high strength and high modulus fibers of nylon 6 , nylon 66, and poly(ethylene terephthalate) on commercial base. According to the reports of Shimizu et al., ${ }^{10-13)}$ the orientational degree of molecular chains became larger as the velocity of the spinning increased. However, their recent work showed that beyond the velocity of $6000 \mathrm{~m} /$ $\min ,{ }^{12-13)}$ there existed ununiform structures whose molecular orientational degree, crystallinity, and birefringence at the skin within fibers are higher than those at the core and such a tendency becomes considerable with increasing the velocity taken-up. They pointed out that such a radial variation becomes an obstacle to promote mechanical properties of fibers.

The gel deformation has been well-known as ultradrawing method to produce polyethylene fiber with high modulus and high tensile strength. ${ }^{14-20)}$ This method was first proposed by Smith and Lemstra. ${ }^{14-16)}$ The dry gel film as a specimen was produced by gelation/crystallization from dilute solutions by using polyethylene with molecular weight greater than $1 \times 10^{6}$. This procedure has been proposed to solve the fault that the attainable draw ratio of melt-crystallized material decreases with increasing molecular weight and samples with molecular weight greater than $1 \times 10^{6}$ cannot be drawn to ratio higher than $5-10.21-22)$ In our recent work, ${ }^{23)}$ it was found that for a sufficiently high molecular weight, the maximum achievable draw ratio depends principally on the concentration of the solution from which the gel was made. This phenomenon was attributed to a reduced number of entanglements per molecules in solution cast/spun polymers in comparison with those obtained from the melt. Therefore it is of interest to determine an optimum level of entanglements which can be realized by a proper choice of the solution concentration. This approach was carried out by the measurement of solution viscosity, since it is basically related to the size or extension in space of the macromolecules. The viscosity-concentration data indicated that there exists an apparent critical concentration range where there is an abrupt change in the concentration dependence of the viscosity. This critical concentration is assumed to correspond to the onset of overlap of the randomly coiled molecules in solutions. Films produced by gelation/crystallization from solutions, the critical concentration being $0.4 \mathrm{~g} / 100 \mathrm{ml}$, could be readily elongated to a draw ratio of $\lambda=300 .{ }^{23)}$ For such ultradrawn films, the Young's modulus and the tensile strength attained to 202 and $6.2 \mathrm{GPa}$, respectively. These are among the highest values reported for polyethylene. ${ }^{8-9) .24 \text { ) }}$

In our present work, current interest is concentrated on the elongation behavior up to $\lambda=300$ in terms of morphological aspect in order to study the origin of the considerable drawability of the dry gel film. The investigation is carried out by using scanning electron microscopy, polarized microscopy, small angle X-ray scattering (SAXS), wide angle X-ray diffraction (WAXD), and small angle light scattering (SALS).

\section{EXPERIMENTAL SECTION}

A linear polyethylene with a molecular weight of $4 \times 10^{6}$ (Hercules 1900/90189) was used as a specimen. The solvent was decalin. The solution containing $0.4 \mathrm{~g} / 100 \mathrm{ml}$ of polyethylene and $0.1 \%$ $w / w$ of the anti-oxidant di-t-butyl-p-cresol was prepared by heating the well-blended polymer/ solvent mixture at $150^{\circ} \mathrm{C}$ for $40 \mathrm{~min}$ under nitrogen. The above concentration was the critical one obtained by the measurement of solution viscosity. For the large volumes $(1500 \mathrm{ml})$ of solution required for preparing the gels, $150^{\circ} \mathrm{C}$ was demonstrated to be the lowest temperature for effective disolution with minimum degradation through trial and error. The homogenized solution was poured into an aluminum tray that was surrounded by ice water to form a gel. The decalin was allowed to evaporate from the gels under ambient condition for 30 days. The nearly dried film, which had a thickness of about $300 \mu \mathrm{m}$, was immersed in an excess of ethanol for 30 days to remove the anti-oxidant and subsequently vacuumdried for 1 day to remove residual traces of the decalin-ethanol mixture. The strip was clamped in a manual stretching device in such a way that the length to be drawn was $2 \mathrm{~mm}$.

The specimen was held at $135^{\circ} \mathrm{C}$ for $15 \mathrm{~min}$ in an oven and elongated manually up to the desired 
ratio below $\lambda=300$. The elongation temperature was decided from the profile of the DSC curve which exhibited the beginning of melting around $135^{\circ} \mathrm{C}$ and the maximum of melting peak around $140^{\circ} \mathrm{C}^{23)}$ Immediately after stretching, the stretcher with the sample was quenched to room temperature for $30 \mathrm{~min}$. Draw ratios were determined in the usual way by measuring the displacement of ink marks placed $1 \mathrm{~mm}$ apart on the specimen prior to drawing. The elongation up to higher draw ratios beyond $\lambda=100$ was done in two steps. This is due to the difficulty in obtaining drawn films beyond $\lambda=100$ in one step because of the physical restriction of the size of the oven. Thus, the specimen with an original length of $4 \mathrm{~mm}$ (i.e., the length to be stretched), was drawn to $\lambda=50$ in the first step and the drawn film was cut into strips of length $50 \mathrm{~mm}$. These specimens, each clamped over a length of $10 \mathrm{~mm}$ at the end and the length to be stretched being $30 \mathrm{~mm}$, were drawn up to the desired ratios beyond $\lambda=100$ in the second step using the method discussed above. The Young's modulus and the tensile strength for the specimens, the length to be drawn being 20 $\mathrm{mm}$ and the width being $3-5 \mathrm{~mm}$, were measured with an Instron testing instrument at a temperature of $20^{\circ} \mathrm{C}$ and at cross head speed of $10 \mathrm{~mm} / \mathrm{min}$. These results which will be reported elsewhere ${ }^{23}$ ) in detail, are represented as Figure 1 for reference.

Density of films was measured by a pycnometer with xylene-carbon tetrachloride as the medium. Since the residual anti-oxidant are very dependent on the density, great care was taken to remove the anti-oxidant. When the specimen was drawn beyond $\lambda=200$, most of the residual anti-oxidant appeared on the film surface, because of the thin film thickness less than $2 \mu \mathrm{m}$. Then the drawn specimens were immersed in an excess of ethanol for 30 days prior to measuring the density and subsequently vacuum-dried for 1 day. After then the film surfaces were brushed off. Through such a process, it would be expected that most of the residual anti-oxidant were removed. For the specimens drawn above $\lambda=200$, these densities were equal to unity within the experimental error, which corresponds to the theoretical density of the polyethylene crystal. By contrast, it was very difficult to remove the residual anti-oxidant from undrawn film, because of the thick film thickness

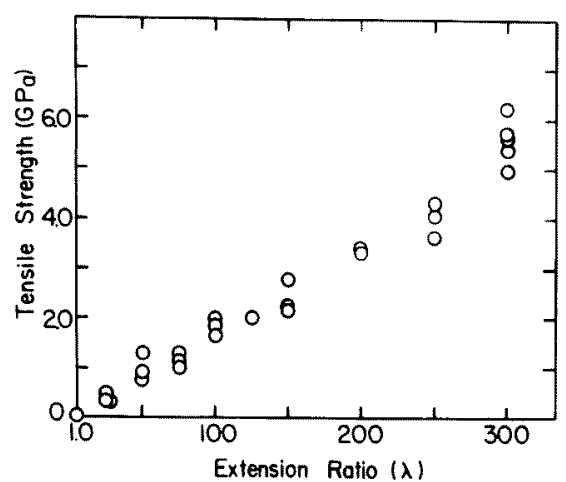

(a)

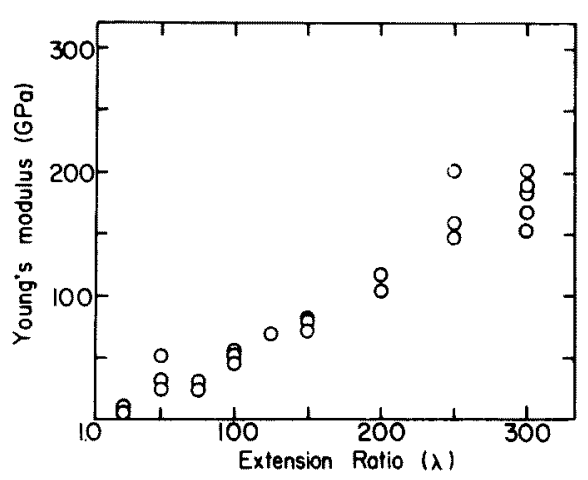

(b)

Fig. 1. Mechanical properties of ultradrawn polyethylene gel films; (a) relationship between the Young's modulus and draw ratio of $\lambda$, (b) relationship between the tensile strength and draw ratio $\lambda$. Cross head speed $1 \mathrm{~cm} /$ min. These relationships will be appeared elsewhere. $^{23)}$

of about $300 \mathrm{~m} \mu$. Therefore, only the specimen used to measure the density was prepared without anti-oxidant by neglecting the degradation of polymer chains. The density measured is $0.988 \mathrm{~g} /$ cc, which corresponds to a crystallinity about $92 \%$.

Scanning electron micrographs were obtained by JSM-T300 in JEOL Co., Ltd. and X-ray patterns were obtained with $\mathrm{Ni}$-filtered $\mathrm{Cu} \mathrm{K} \alpha$ radiation at $40 \mathrm{~mA}$ and $20 \mathrm{KV}$. Light scattering patterns were recorded using $3 \mathrm{~mW}$ He-Ne gas laser as a light source. Diffuse scattering was avoided by sandwiching the specimen between cover glasses with silicon oil (refraction index 1.533) as an immersion fluid. 


\section{RESULTS AND DISCUSSION}

Figure 2 shows the change in the appearance of a specimen with increasing elongation ratio of $\lambda$ under scanning electron microscopy. The fibrillar texture in undeformed state shows like spongy tissue. The existence of fibrillar textures prepared without stress is very interesting because it is wellknown that polyethylene crystallized from stressed polymer melts and solutions has fibrillar (rodlike) textures whereas that crystallized without stress has spherulitic textures. This reason is presumably due to many constitutional factors such as molecular weight, quenching temperature, and solution concentration.

With increasing $\lambda$, the width of fibrillar texture is decreased and finally the fibrillar textures seem to be disruptively deformed into fine filaments. The filaments are also highly oriented parallel to the drawing direction. As illustrated in a series of photographs, this tendency becomes clear beyond $\lambda=20$. The crystallinity of the undeformed gel film is almost $92 \%$ and this result indicates the fibrillar texture almost consists of crystal region.

In order to clarify the deformation behavior of the fibrillar textures, some detailed scanning electron micrographs are shown in Figures 3-7 except Figure 6. Figure 3(a) and (c) display the micrographs of specimens at $\lambda=1$ (undeformed state) and $\lambda=1.5$ and (b) and (d) in enlargement. As illustrated in the four micrographs, observations revealed that fibrillar textures like spongy tissue comprised interconnected lamellar crystals. With further elongation up to $\lambda=5$, the micrographs (a) and (c) in Fig. 4 indicate that the cross-linking loci appeared to consist of fibrillar shish-Kabab-like crystals which were arranged in the drawn direction. The enlarged micrographs (b) and (d) illustrate the abundance of micronecking of fibrils and the fine filaments teared in some places.

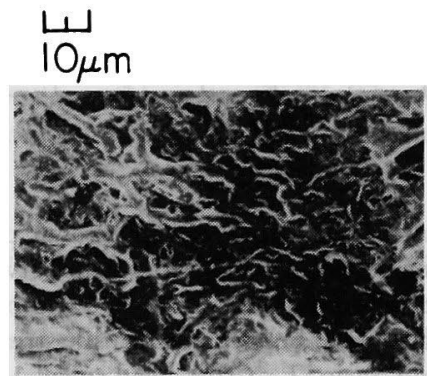

(a) $\lambda=1.0$

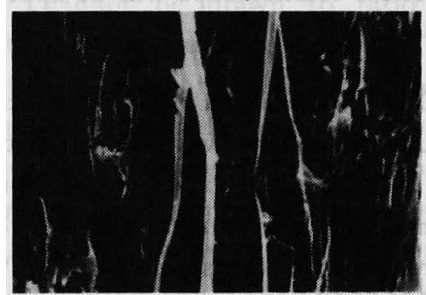

(d) $\lambda=5.0$

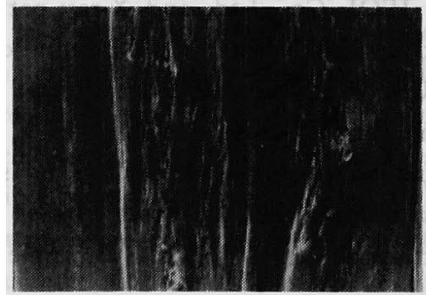

(g) $\lambda=75$

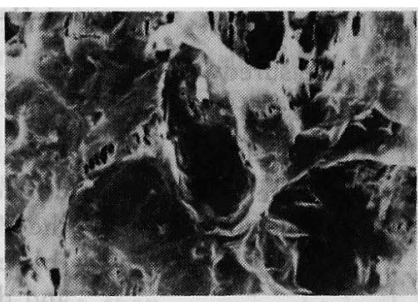

(b) $\lambda=1.5$

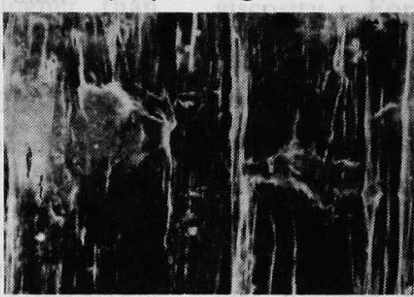

(e) $\lambda=7.0$

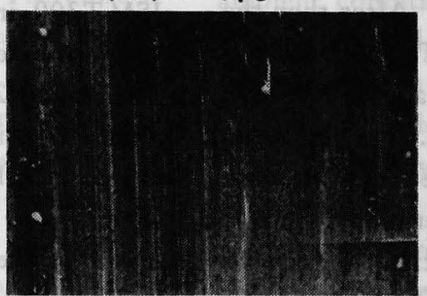

(h) $\lambda=150$

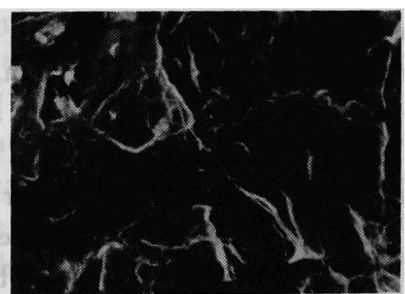

(c) $\lambda=2.0$

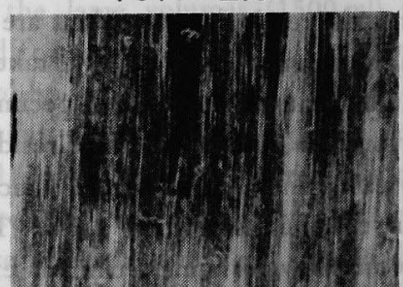

(f) $\lambda=20$

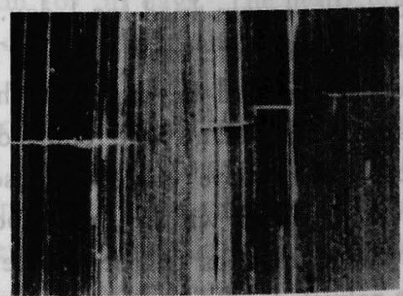

(i) $\lambda=300$

Fig. 2. Scanning electron micrographs of films drawn up to $\lambda=300$. 

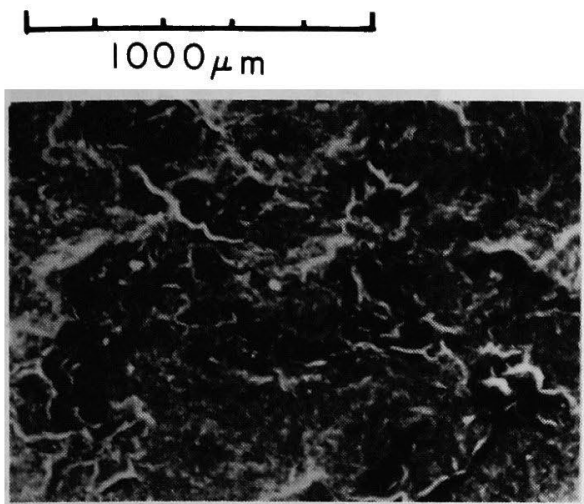

(a) $\lambda=1.0$

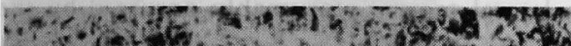
s.t?

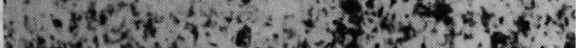

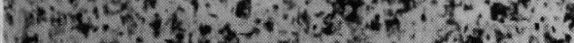

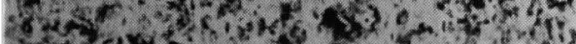

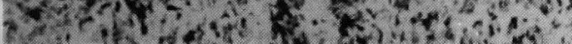

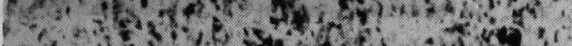

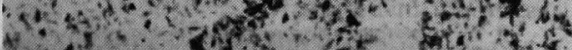

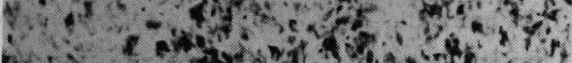

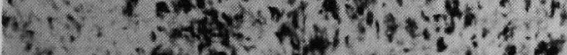
7. tis ifs (c) $\lambda=1.5$

\section{$\frac{1}{100 \mu \mathrm{m}}$}

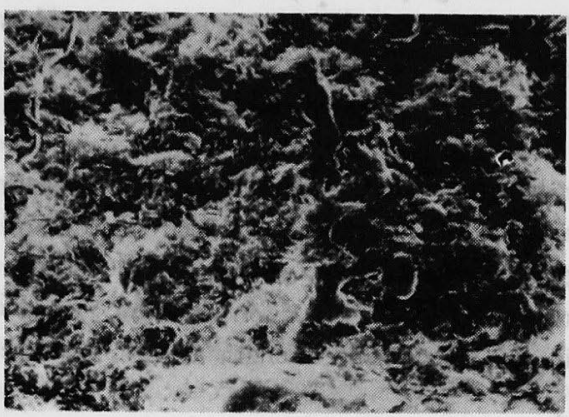

(b) $\lambda=1.0$

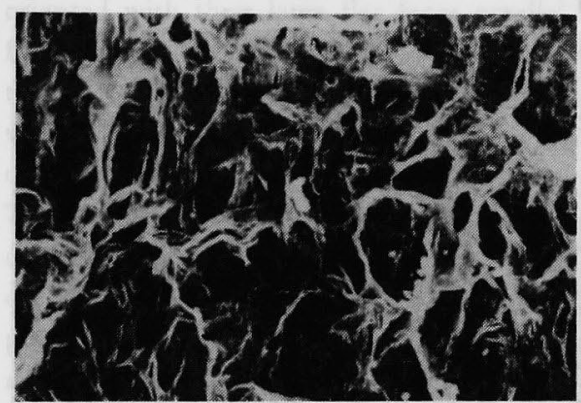

(d) $\lambda=1.5$

Fig. 3. Scanning electron micrographs of films drawn up to $\lambda=1.5$.

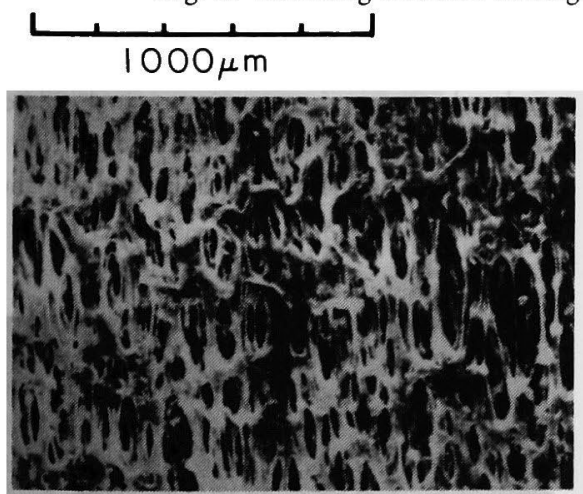

(a) $\lambda=3.0$

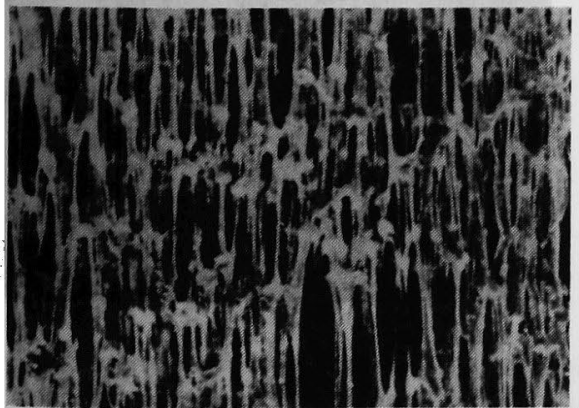

(c) $\lambda=50$

\section{$100 \mu \mathrm{m}$}

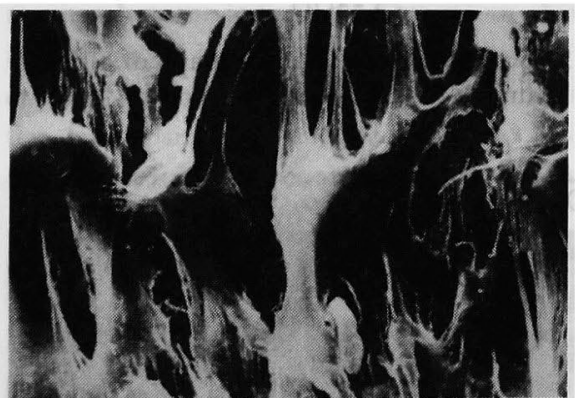

(b) $\lambda=3.0$

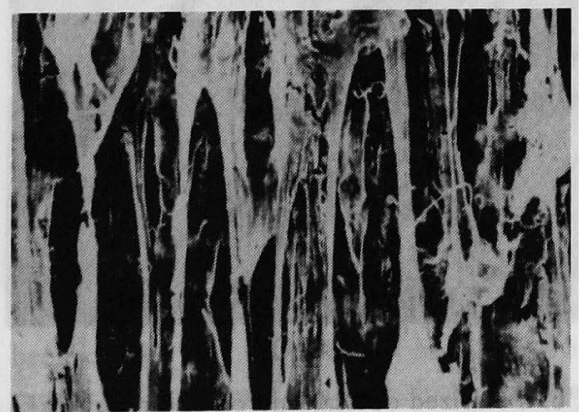

(d) $\lambda=5.0$

Fig. 4. Scanning electron micrographs of drawn films at $\lambda=3$ and 5 . 
Figures 5 and 6 show scanning electron and polarized micrographs of specimen drawn to $\lambda=$ 300. The micrograph in Figure 5 is represented as a typical example to emphasize that there are a number of voids on the drawn film surface. In actual fact, the size of voids observed generally was smaller than that shown in Figure 5. Even in the existence of voids, the polarized micrograph in Figure 6 displays uniform smooth surface. Here, the question can be arisen why the Young's modulus and the tensile strength at $\lambda=300$ were

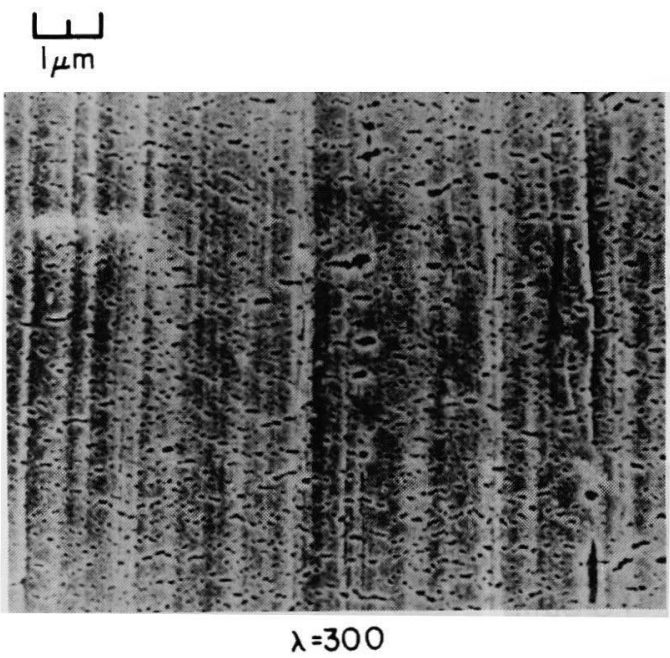

Fig. 5. Scanning electron micrograph of a film drawn to $\lambda=300$.

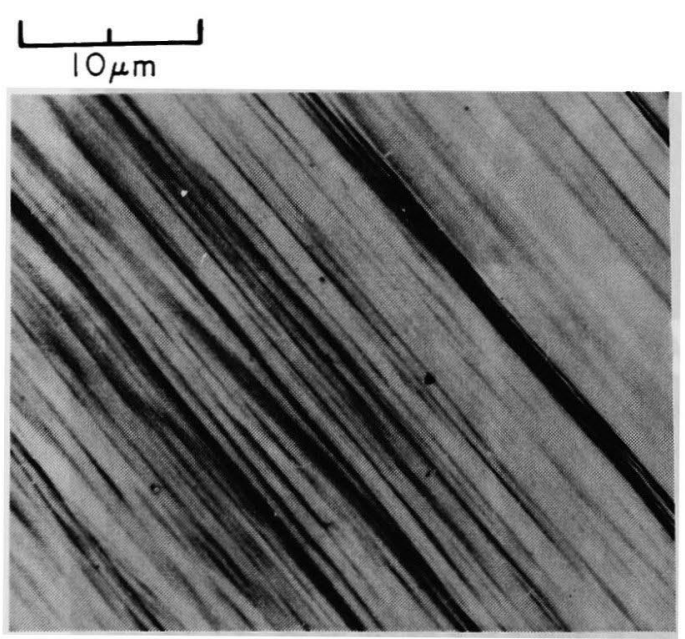

$\lambda=300$

Fig. 6. Polarized optical micrograph of a film drawn to $\lambda=300$.
202 and $6.2 \mathrm{GPa}$, respectively, which are among the highest reported values for polyethylene at room temperature in spite of a number of voids. The reason for this discrepancy remains to be resolved. ${ }^{25)}$ On the other hand, the mechanical property in the transverse direction became poorer as draw ratio increased.

Figure 7 shows a scanning electron micrograph of the specimen $(\lambda=300)$ broken by Instron instrument to measure the tensile strength at $20^{\circ} \mathrm{C}$. Break lines run in the transverse direction and the fine filaments were interconnected cross to cracks along the stretching direction. The cracks due to lateral tearing presumably occurred by the impact when the specimen was broken. Such a phenomenon was observed very often as a fibrillation increased considerably with increasing $\lambda$. Incidentally, a number of voids shown in Figure 5 can not be observed with such a lower magnification as shown in Figure 7.

Figure 8 shows WAXD patterns observed from drawn specimens when the X-ray beam was directed along the stretching direction (end view). As discussed in the recent papers, ${ }^{17-19)}$ the pattern (a) indicates the preferential orientation of the crystal c-axes perpendicular to the film surface. The pattern (b) at $\lambda=5$ suggests that the most of molecular c-axes become increasingly tilted toward the stretching direction to transform from a folded to a fibrous crystals and consequently the crystal

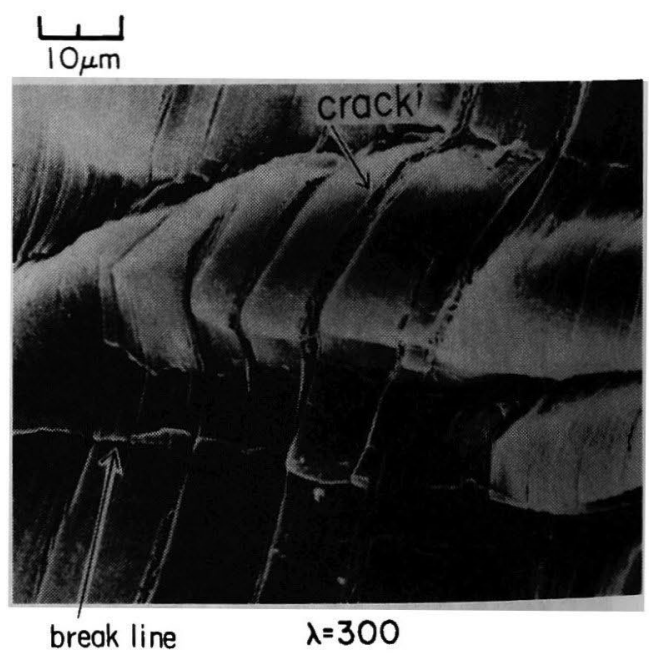

Fig. 7. Scanning electron micrograph of broken place of a film drawn to $\lambda=300$. 


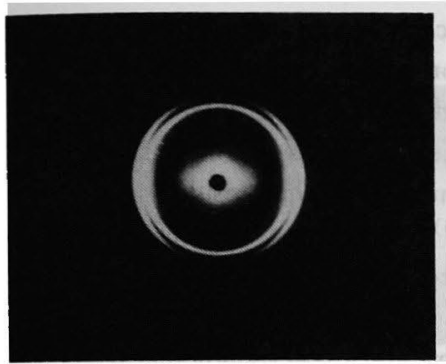

(a) $\lambda=1$

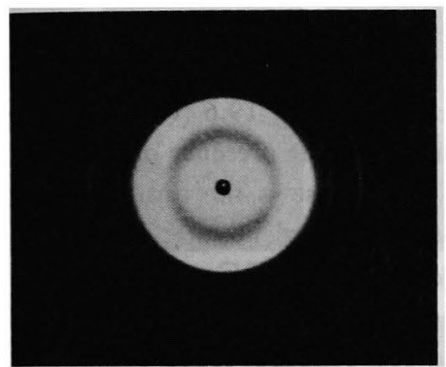

(b) $\lambda=5$

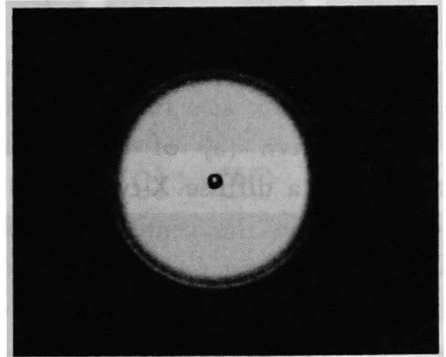

(c) $\lambda=10$

Fig. 8. WAXD patterns from films drawn up to $\lambda=10$ (end view).

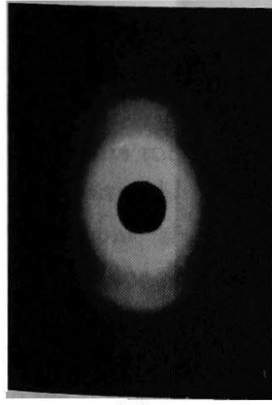

(a)

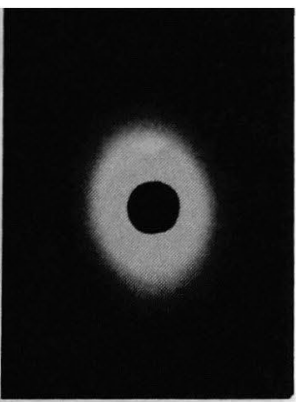

(b)
Fig. 9. SAXS patterns from films. (a) the unannealed specimen, (b) the annealed specimen for $15 \mathrm{~min}$ at $135 \mathrm{C}$. (end view) c-axes are almost randomly oriented around the stretching direction. In order to obtain more conclusive evidence for this mechanism, SAXS experiment was carried out.

Figure 9 shows SAXS patterns from two kinds of dry gel films undeformed (end view). The patterns (a) and (b) correspond to the scattering from the specimen unannealed and the specimen annealed for $15 \mathrm{~min}$ at $135^{\circ} \mathrm{C}$, respectively. As discussed already, ${ }^{17-19}$ ) the WAXD pattern (a) in Figure 7 and the SAXS pattern (a) in Figure 8 together indicate that the dried gel film unannealed is composed of crystal lamellae which are highly oriented with their large flat faces parallel to the film surface but randomly oriented with respect to the direction normal to the film surface and within the crystal lamella, the crystal c-axes are oriented perpendicular to the large flat faces. Thus when the as-cast polyethylene gel films are dried by slow evaporation of the solvent, the constituent lamellar crystals become oriented parallel to the film surface in a manner similar to mats of single crystals. In addition, it would be expected that, in relation to the photograph (a) in Figure 1, the fibrillar textures comprise the crystal lamellae discussed above. The pattern (b) from the annealed specimen displays that the scattering maxima become indistinct. This means that there is an increase in the orientational disorder of the crystal lamellae that are oriented with their large flat faces parallel to the film surface. This fluctuation probably causes an increase in the entanglement mesh leading to interpenetration of chains from neighbouring crystals. ${ }^{18-19)}$

Judging from the WAXD patterns in Figure 7 and the SAXS ones in Figure 8, it may be deduced that the random orientation of the crystal c-axes around the stretching direction is due to the transformation from a folded to a fibrous crystals. Furthermore, it may be expected that the fibrillar shish-Kabab-like crystals shown in Figure 3(a) consist of the coexistence of fibrous and folded crystals on the process of the transformation. Thus, we may conclude that the ultradrawing process of the dry gel film is essentially similar to the drawing one of single crystal mats which has been carried out by Ishikawa et al. ${ }^{26}$ ) This indicates that the transformation from a folded to a fibrous crystals is essential to realize the high 
drawability. The difference of morphological properties between dry gel films with high drawability and single crystal mats is attributed to the existence of a suitable level of the entanglements that act as intermolecular crosslinks and effectively transmit the drawing force. In single crystal mats, a molecular chain is completely incorporated into a lamellar crystal and the lamellae are not interconnected by the chain molecules. Accordingly, when the lamellae transform to fibrous textures with increasing draw ratio, chain slippage must occur in the process. By contrast, as discussed in the previous paper, ${ }^{17-19)}$ the dry gel films crystallized from the solution with critical concentration ensure the existence of a suitable level of the entanglement.

Figure 10 shows WAXD patterns from dry gel films drawn to $\lambda=300$ when the incident beam was along the film normal direction (through view). The pattern (a) was obtained from one film and the pattern (b) from five thickness of film. The strong air scattering appeared for a long exposure time, since there are a very few number of crystallites within the film with the thickness of about $1 \mu \mathrm{m}$. The air scattering was one of unavoidable factors, as it is very difficult to pile up the several films in such a manner that the stretching directions of each film are in the same direction. Actually, as can be seen in the two patterns, the reflection spots from five thickness of film be- comes clear but broader in comparison with those from one film. Anyway the crystal c-axes are oriented almost perfectly in the drawn direction. The orientational mode is uniaxial, which is quite different from the result observed by Smith et al. ${ }^{16)}$ According to their report, ${ }^{16)}$ the film drawn to $\lambda=130$ exhibited high orientation of the $b$-axis in the plane of the film and, therefore, the a-axis orientation perpendicular to the film surface. Apart from the typical (110) and (200) reflections of the orthorhombic polyethylene unit cell, the pattern (b) displayed rather strong diffraction spots at an angle of 19.6 (twice the Bragg angle), which is due to the presence of the triclinic cell. ${ }^{27)}$ The triclinic phase is the unstable crystal modification of polyethylene that has frequently been observed in strained crystals. The co-existence of orthorhombic and triclinic cells has been also observed for cold drawn specimens as far as polyethylene powder produced by Hercules Co., Ltd. was used. ${ }^{17-19)}$

Figure 11 shows SALS patterns under $\mathrm{Hv}$ polarization condition as a function of draw ratio of $\lambda$. The pattern (a) of the undrawn film displays lobes of a diffuse X-type. The intensity had a maximum in the center and it decreased monotonically with increasing scattering angle. The scattering pattern appears at a very low scattering angle in comparison with the ones that had been reported previously for collagen ${ }^{28)}$ and

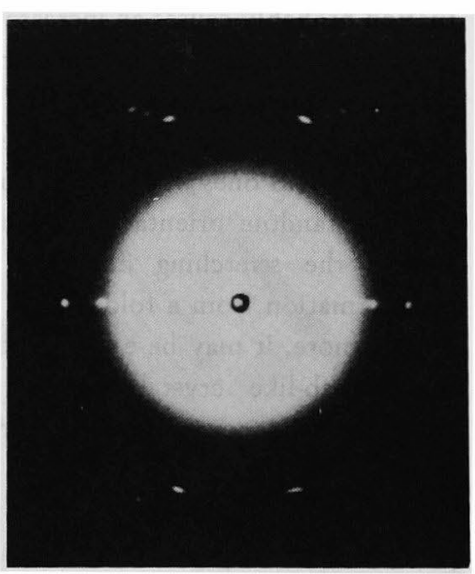

(a)

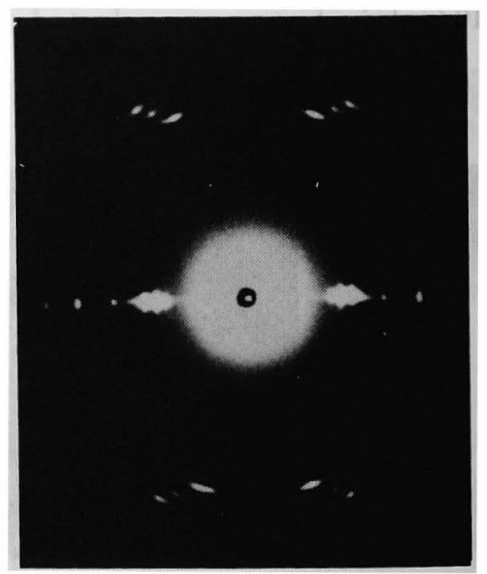

(b)

Fig. 10. WAXD patterns for films drawn to $\lambda=300$. (a) the pattern from one film, (b) the pattern from five thickness of film. (through view) 


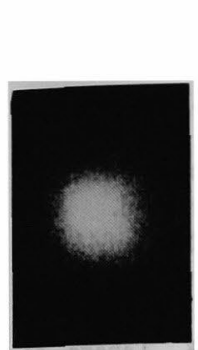

(a) $\lambda=1$

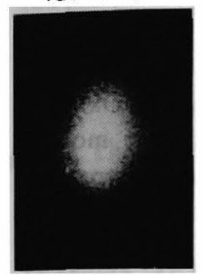

(b) $\lambda=5$

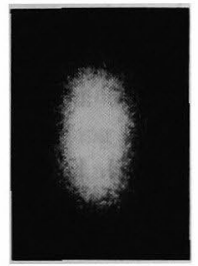

(c) $\lambda=10$

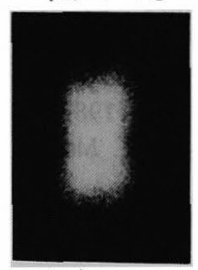

(d) $\lambda=15$

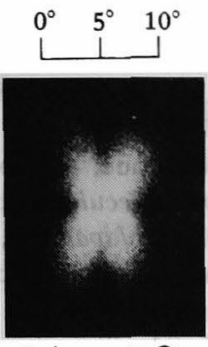

(e) $\lambda=20$

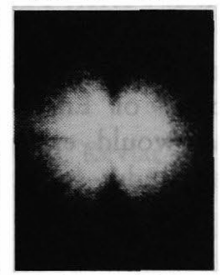

(f) $\lambda=25$

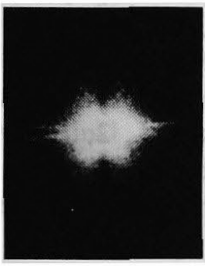

(g) $\lambda=30$

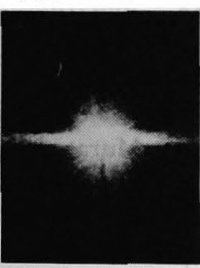

(h) $\lambda=50$

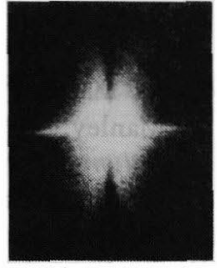

(i) $\lambda=75$

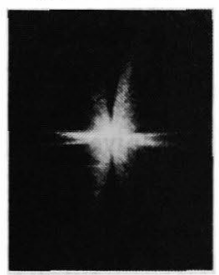

(j) $\lambda=100$

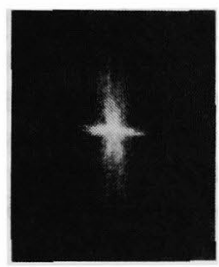

$(k) \lambda=200$

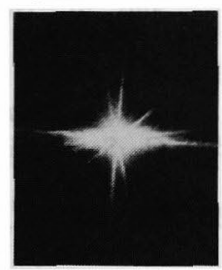

(1) $\lambda=300$

Fig. 11. SALS patterns as a function of draw ratio of $\lambda$.

poly(tetrafluoroethylene) ${ }^{29)}$ and in addition, the notch of the four lobes is less clearly defined. Such a pattern presumably indicates the existence of large-size rods with finite length and width, the optical axes being oriented normal to the film surface but showing orientation disorder with respect to the rod axis. The orientation of molecular (optical) axes was demonstrated by the WAXD pattern when the X-ray beam was directed parallel to the film surface (see Figure 8(a)). The rodlike textures reflecting the light scattering pattern correspond to fibrillar textures observed under scanning electron microscopy. As for sample drawn up to $\lambda=10$, the scattering shows the

indistinct pattern whose lobes are extended in the vertical direction. On the range of $\lambda=15-20$, the scattering shows the four-leaf pattern with azimuthal angle dependence of scattered intensity distribution. Such patterns have been observed under the oriented crystallization process for poly(ethylene terephthalate) $)^{30-31}$ and poly(tetramethylene terephthalate)..$^{32-33)}$ Beyond $\lambda=25$, the scattering lobes are extended in the horizontal direction and the sharp streaks in addition to the lobes also appeared in the horizontal direction. As the draw ratio increases, the scattering lobes are indistinct. Finally, at $\lambda=300$, the pattern displays sharp streaks due to the scattering from cracks and/or fine filaments shown in micrograph (i) in Figure 1. However, detailed correspondence between the SALS patterns in Figure 11 and the scanning electron micrographs in Figure 1 remains further investigation.

Finally, we may emphasize that the ultradrawn method using the dry gel film which is produced by gelation/crystallization from a solution with a critical concentration is the best to produce strong polyethylene fiber and it stands a good possibility to industrialize near future. This technique will be also successful in producting strong fiber of polypropylene. However, it has been very difficult to apply this technique to another polymers such as poly(ethylene terephthalate), nylon 6 , and nylon 66. Therefore, the further progressive investigation must be promoted.

\section{Acknowledgement}

We thank to Professor Kawai, Hyogo Education College for valuable comments and suggestions. Thanks are due to Professor Ito, Kyoto University of Industrial Arts and Textile Fibers for measuring $\mathrm{X}$-ray diffraction patterns and valuable suggestions.

\section{References and Note}

1) M. Matsuo, F. Ozaki, Y. Konno and T. Ogita, J. Polym. Sci., Polym. Phys. Ed., 19, 1531 (1981)

2) F. Ozaki, T. Ogita and M. Matsuo, Macromolecules, 14, 299 (1981)

3) M. Matsuo, K. Kakei, Y. Nagaoka, F. Ozaki, M. Murai and T. Ogita, J. Chem. Phys., 75, 5911 (1981)

4) M. Matsuo, K. Kakei and Y. Nagaoka, $J$. Chem. Phys., 75, 5925 (1981) 
5) M. Matsuo, K. Kakei, F, Ozaki and T. Ogita, J. Chem. Phys., 76, 3974 (1982)

6) W. J. Toth and A. V. Tobolsky, J. Polym. Sci., Polym. Lett. Ed., 8, 531 (1970)

7) E. Iizuka, T. Keira and A. Wada, Mol. Cryst. Liq. Cryst., 23, 13 (1973)

8) J. Smook, J. C. Torfs, P. F. van Hutter and A. J. Pennings, Polymer Bulletin, 2, 293 (1980)

9) P. J. Barham and A. Keller, J. Material Sci., 15, $2229(1980)$

10) J. Shimizu, K. Toriumi and K. Tamai, Sen-i Gakkaishi, 33, T-208 (1977)

11) J. Shimizu, N. Okui, T. Kikutani and K. Toriumi, Sen-i Gakkaishi, 34, T-93 (1978)

12) J. Shimizu, N. Okui and T. Kikutani, Sen-i Gakkaishi, 37, T-135 (1981)

13) J. Shimizu, N. Okui, T. Kikutani, A. Ono and A. Takaku, Sen-i Gakkaishi, 37, T-143(1981)

14) P. Smith and P. J. Lemstra, J. Material Sci., 15,505 (1980)

15) P. Smith and P. J. Lemstra, J. Polym. Sci., Polym. Phys. Ed., 19, 877 (1981)

16) P. Smith, P. J. Lemstra, J.P.L. Pijpers and A. M. Kiel, Colloid \& Polym. Sci., 259, 1070 (1981)

17) M. Matsuo and R. St. J. Manley, Macromolecules, 15, 985 (1982)

18) M. Matsuo and R. St. J. Manley, Macromolecules, 16, 1500 (1983)

19) M. Matsuo, M. Tsuji and R. St. J. Manley, Macromolecules, 16, 1505 (1983)

20) M. Matsuo, C. Sawatari, M. Tsuji and R. St. J. Manley, J. Chem. Soc., Faraday Trans. II. 79, 1593 (1983)

21) G. Capaccio, A. G. Gibson and I. M. Ward, Ultra-High Modulus Polymers, A. Ciferri and
I. M. Ward, Eds., Applied Science Publ, London, page 1.

22) S. B. Warner, J. Polym. Sci., Polym. Phys. Ed, 16, 2139 (1979)

23) M. Matsuo, K. Inoue, N. Abumiya, R. St. J. Manley, Macromolecules, submitted.

Polymer Preprints, Japan, 32, No. 4, 841-842, (1983) at the meeting of polymer science, Japan.

24) T. Kanamoto, A. Tsuruta, K. Tanaka, M. Takeda and R. S. Porter, Polymer J., 15, 327 (1983)

25) As the private communication with Prof. Monobe, Faculty of Engineering, Okayama University, we would expect that most of voids observed under scanning electron microscopy do not penetrate through sample and they are a sort of cavity.

26) K. Ishikawa, K. Miyasaka and M. Maeda, $J$. Polym. Sci., Part A-2, 7, 2029 (1969)

27) P. H. Geil, J. Polymer Sci., Part A, 2, 3813 (1964)

28) M. Moritani, N. Hayashi, A. Utsuo and $H$. Kawai, Polymer J., 2, 74 (1971)

29) T. Hashimoto, Y. Murakami and H. Kawai, J. Polym. Sci., Polym. Phys. Ed., 13, 1613 (1975)

30) M. Matsuo, M. Tamada, T. Terada, C. Sawatari and M. Niwa, Macromolecules, 15, 988 (1982)

31) T. Terada, C. Sawatari, T. Chigono and $M$. Matsuo, Macromolecules, 15, 998 (1982)

32) C. Sawatari, T. Muranaka and M. Matsuo, Polymer J., 15, 33 (1983)

33) C. Sawatari, M. Iida and M. Matsuo, Macromolecules, in press.

\section{0 倍まで延伸された乾燥ゲルポリエチレンの変形機構}

\section{奈良女子大学家政学部 松生 勝，井上佳保里，鐙谷憲子}

300培まで延伸しうる乾燥ポエチレンフィルムの变 形機構を走查型電子顕锺鏡，偏光蹎微鏡，小角 X線散乱， 広角X線回折，及び小角光散乱法を用いて形態学的見地 から研究した。一連の㬰験結果より，乾燥ゲルフィルム の形態は単結晶マットの形態に類似し，従って延伸可
能ならしめるのは，折りたたみ結晶からつィブリル状䊅 晶への転換による手のと考えられる。延伸你しては， 結晶ラメラ間の適当な数のエンタングルメントが分子間 の架橋として延伸力を伝達するための重要な役割をはた す。 